Research Article

\title{
Experimental Study on the Dynamic Modulus and Damping Ratio of Compacted Loess under Circular Dynamic Stress Paths
}

\author{
Liguo Yang $\mathbb{D}^{1,2}$ Shengjun Shao $\mathbb{D}^{1,3}$ and Zhi Wang ${ }^{1}$ \\ ${ }^{1}$ Institute of Geotechnical Engineering, Xi' an University of Technology, Xi'an 710048, Shaanxi, China \\ ${ }^{2}$ Department of Civil and Traffic Engineering, Yellow River Conservancy Technical Institute, Kaifeng 475003, Henan, China \\ ${ }^{3}$ Shanxi Key Laboratory of Loess Mechanics and Engineering, Xi' an University of Technology, Xi' an 710048, Shaanxi, China
}

Correspondence should be addressed to Liguo Yang; vk2006ylq@163.com

Received 30 July 2021; Revised 23 September 2021; Accepted 25 September 2021; Published 14 October 2021

Academic Editor: Iman Mansouri

Copyright ( $\odot 2021$ Liguo Yang et al. This is an open access article distributed under the Creative Commons Attribution License, which permits unrestricted use, distribution, and reproduction in any medium, provided the original work is properly cited.

\begin{abstract}
Dynamic loads such as earthquakes and traffic will simultaneously generate vertical dynamic stress and horizontal shear stress in the foundation soil. When the vertical dynamic stress amplitude is twice the horizontal shear dynamic stress amplitude, and the phase difference between them is $90^{\circ}$, a circular dynamic stress path is formed in the $\tau_{z \theta d} \sim\left(\sigma_{\mathrm{zd}}-\sigma_{\theta d}\right) / 2$ stress coordinate system. To simulate the stress state of soil in the area of the circular dynamic stress path caused by bidirectional dynamic stress coupling, a series of tests of compacted loess under the action of a circular dynamic stress path were carried out using a hollow cylindrical torsion shear apparatus. The effects of the mean principal stress, dry density, and deviatoric stress ratio (the ratio of deviator stress to average principal stress) on the dynamic modulus and damping ratio of compacted loess were mainly studied. The test results show that, under the action of the circular dynamic stress path, the larger the mean principal stress is, the larger the dynamic compression modulus and dynamic shear modulus are. The dynamic compression modulus increases obviously with increasing dry density, but the dynamic shear modulus increases only slightly. When the deviator stress ratio increases from 0 to 0.4 , the dynamic compression modulus and dynamic shear modulus increase to a certain extent. In addition, the greater the dry density and deviatoric stress ratio are, the greater the initial dynamic compression modulus and initial dynamic shear modulus of the compacted loess. The dynamic compression damping ratio of compacted loess increases with increasing mean principal stress, but the dynamic shear damping ratio decreases with increasing mean principal stress. Dry density basically has no effect on the dynamic compression damping ratio and dynamic shear damping ratio of compacted loess. When the dynamic strain exceeds $1 \%$, the greater the deviatoric stress ratio is, the smaller the dynamic compression damping ratio and the dynamic shear damping ratio are. The research results can provide reference for the study of dynamic modulus and damping ratio of loess under special stress paths.
\end{abstract}

\section{Introduction}

The dynamic modulus and damping ratio are the basis of foundation engineering seismic design, seismic stability evaluation, settlement prediction, and other works. Researchers also attach great importance to this research work and carry out a series of studies on various types of soil through field tests, indoor resonant column tests, dynamic triaxial tests, and dynamic torsional shear tests [1-4]. In actual engineering, dynamic loads such as earthquakes, traffic, waves, and other dynamic loads produce vertical dynamic stress and horizontal dynamic stress in foundation soil. The amplitude and direction of the dynamic stress are constantly changing, resulting in continuous rotation of the principal stress axis in foundation soil. Inevitably, there will be areas acting on elliptical and circular dynamic stress paths $[5,6]$. There are many factors that affect the dynamic characteristics of soil $[7,8]$. The dynamic stress path is one of the important factors that affect the dynamic deformation characteristics of soil. Therefore, research on the dynamic modulus and damping ratio of soil under special dynamic stress paths is more consistent with the actual situation and can obtain more accurate variation rules of the dynamic modulus and damping ratio. 
Research on special dynamic stress paths of soil dynamics begins with the rotation of the principal stress axis. With the continuous development and improvement of hollow cylindrical torsion shear apparatuses, many scholars have carried out research on the principal stress axis rotation of different soils, and research on the influence of complex dynamic stress paths on the dynamic characteristics of soils has been deepening. Ishihara et al. [9] analyzed the situation in which the principal stress axis rotation of seabed soil caused by wave loading might appear as a "circular dynamic stress path," and the test simulation showed that the strength of sand under such a stress path was lower than that under ordinary unidirectional cyclic loading. Towhata et al. [5] found that the continuous rotation of the principal stress axis can produce greater excess pore water pressure than that without rotation, which greatly reduces the liquefaction resistance of saturated sand. Miura et al. [10] and Lashkari et al. [11] established a new constitutive model considering principal stress axis rotation to describe the deformation and liquefaction behavior of anisotropic sand. Zhou et al. [12] and Zhang et al. [13] used a hollow cylindrical torsion shear apparatus to carry out saturated silt experiments with different cyclic loading amplitude ratios in axial and torsional and simulated circular dynamic stress paths and elliptical dynamic stress paths, respectively, indicating that the dynamic stress path has a significant influence on the liquefaction of saturated silt. Gu et al. [14, 15] simulated the shear stress and normal stress caused by earthquakes in saturated clay by cyclic triaxial tests with variable confining pressures. The dynamic stress path formed by bidirectional dynamic load coupling is more suitable for simulating the stress field formed by earthquakes in foundations and has a great influence on the strength and pore water pressure of saturated soft clay. $\mathrm{Hu}$ et al. [16] also simulated the figure-eightshaped shear stress path that may be formed by earthquake action and analyzed the influence of the cyclic dynamic stress ratio and frequency on the cumulative cyclic strain and strength. Inam et al. [17], Gallage et al. [18], and Dareeju et al. [19] simulated the rotation of the principal stress axis caused by traffic loads through experiments and proved that the rotation of the principal stress axis has significant effects on the cumulative cyclic plastic deformation of different subgrade soil materials. Qian et al. [20] studied the influence of principal stress rotation caused by traffic loads on the stress-strain behavior of saturated soft clay. Wang et al. [21] compared and analyzed the influence of a nonstandard elliptical stress path and circular stress path on the cyclic strength of seabed sand. Wang et al. [22] tested the circular dynamic stress path formed by the rotation of the principal stress axis of marine soft clay caused by a simulated wave load and studied the changes in pore water pressure and the stress-strain hysteresis curve of soft clay under a long-term cyclic circular dynamic stress path.

The above research simulates the complex dynamic stress path caused by the rotation of the principal stress axis of the soil due to the bidirectional dynamic load coupling caused by earthquakes, traffic, waves, and other dynamic loads, which has a great influence on the dynamic characteristics of saturated sand, silt, and soft clay. However, there are relatively few studies on the dynamic modulus and damping ratio of compacted loess. Cheng et al. [23] carried out experiments on the dynamic modulus and damping ratio of compacted loess under a complex initial stress state and studied the effects of principal stress axis deflection and average principal stress on the dynamic modulus and damping ratio of compacted loess. Wang et al. [24] studied the dynamic modulus and damping ratio of compacted loess under long-term cyclic dynamic loads and evaluated the influence of the number of cycles, confining pressure and dynamic stress on the dynamic modulus and damping ratio of compacted loess. Among them, there is no literature on the dynamic modulus and damping ratio of compacted loess under bidirectional dynamic load.

Loess is widely distributed in China and the world. Compacted loess is widely used in construction engineering foundations, road subgrades, and embankment engineering in these areas. Therefore, this study will use a hollow cylindrical torsion shear instrument to simultaneously apply axial dynamic stress and torsional dynamic shear stress, coupling them to form a circular dynamic stress path, and truly simulate the special dynamic stress path formed by bidirectional dynamic loads. The effects of the mean principal stress, dry density, and deviatoric stress ratio of compacted loess on the dynamic elastic modulus, dynamic shear modulus, dynamic compression damping ratio, and dynamic shear damping ratio under a circular dynamic stress path are mainly studied. The research results of this article can provide references and new ideas for subsequent research.

\section{Materials and Methods}

2.1. Test Equipment. The instrument used in the test is the DTC-199HVS hollow cylindrical torsion shear system produced by SEIKEN Inc. in Japan, which uses a hollow cylindrical sample. The instrument can independently control the axial force $\mathrm{W}$, torque $M_{T}$, internal confining pressure $P_{\mathrm{i}}$, and external confining pressure $\mathrm{P}$, which can not only simulate various complex initial stress states and static stress paths but also independently control the dynamic load applied in four directions. The phase difference of each direction can be controlled to simulate various complex dynamic stress paths. The maximum axial loading force is $20 \mathrm{kN}$, the maximum torque loading is $100 \mathrm{~N} \cdot \mathrm{m}$, and the maximum loading coupling frequency is $5 \mathrm{~Hz}$. The instrument consists of a pressure chamber, hydraulic pump, loading unit, electrical control cabinet, water and air control system, and data collection system, as shown in Figure 1. The data acquisition software was used to automatically record test data points.

2.2. Test Material and Sample Preparation. All the loess materials used in the test were taken from the construction site of a project in Xi'an, China, with a depth of 3-4 m and belonging to Q3 loess. According to ASTM standards, the measured basic physical properties of the loess are shown in Table 1. The grain size distribution curve of loess is shown in 


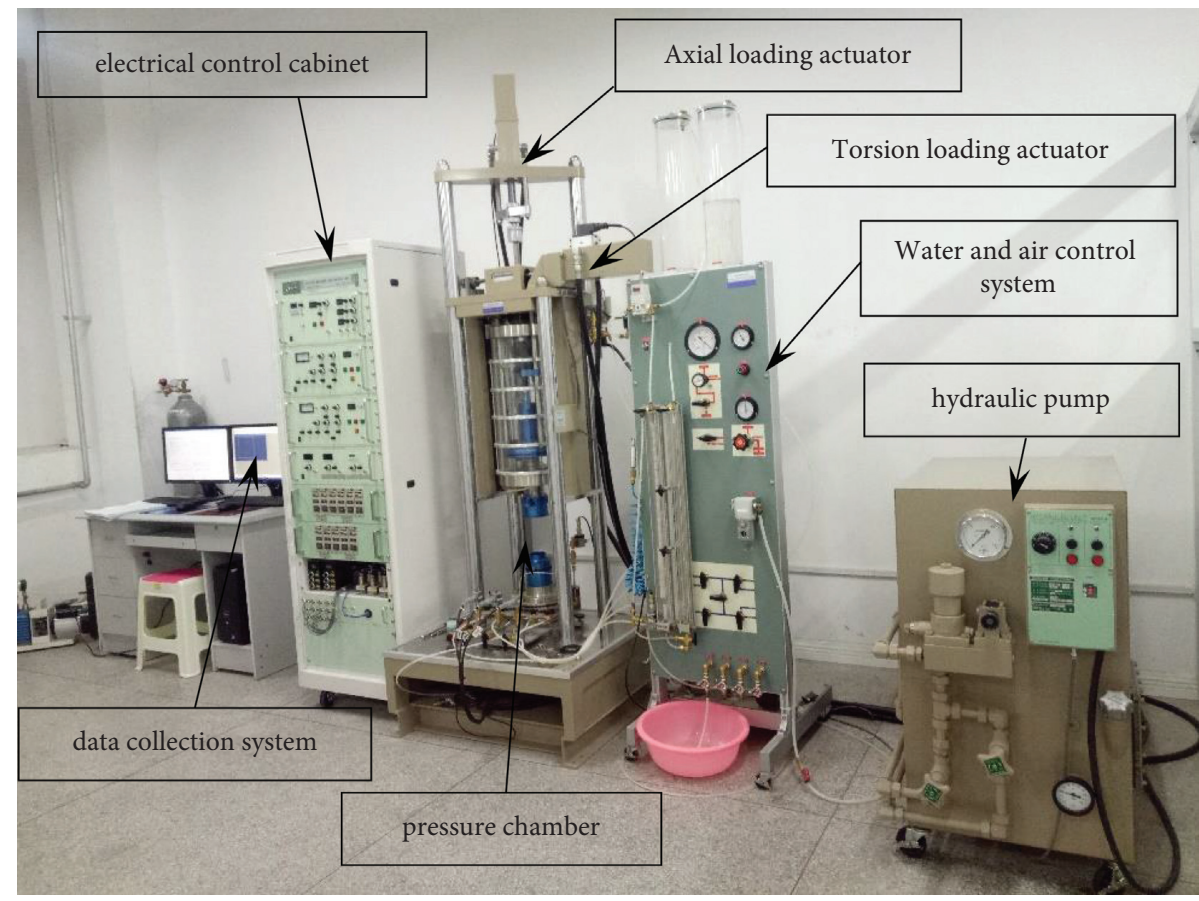

FIgURE 1: Hollow cylindrical torsion shear apparatus.

TABLE 1: Physical properties of loess.

\begin{tabular}{lcc}
\hline Index properties & Value & Specification \\
\hline Specific gravity & 2.70 & ASTM D 854 \\
Liquid limit $(\%)$ & 32 & ASTM D 4318 \\
Plastic limit (\%) & 21 & ASTM D 4318 \\
Plasticity index & 11 & ASTM D 4318 \\
Soil classification & CL & USCS \\
Maximum dry density, $\rho_{d \max }\left(\mathrm{g} / \mathrm{cm}^{3}\right)$ & 1.69 & ASTM D 698 \\
Optimum moisture content, $\omega_{\text {op }}(\%)$ & 20.1 & ASTM D 698 \\
\hline
\end{tabular}

Figure 2. Through the light compaction test, the maximum dry density $\rho_{d \max }$ of loess is $1.69 \mathrm{~g} / \mathrm{cm}^{3}$, and the optimal moisture content $\omega_{o p}$ is $20.1 \%$. The construction of building foundations and road subgrades often takes compactness as the standard of design and evaluation of engineering quality, so this test selects $0.96 \rho_{d \max }, 0.90 \rho_{d \max }$, and $0.85 \rho_{d \max }$ for comparison of three dry densities, namely, $1.62 \mathrm{~g} / \mathrm{cm}^{3}, 1.52 \mathrm{~g} /$ $\mathrm{cm}^{3}$, and $1.44 \mathrm{~g} / \mathrm{cm}^{3}$. Loess taken from the construction site was air-dried, crushed, and passed through a $2 \mathrm{~mm}$ sieve. The water needed to configure the target moisture content was calculated, and the water was evenly sprayed on the soil with a sprayer. Then, the fresh-keeping bag was sealed and placed in the moisturizing container for more than 3 days, and the moisture content was checked until it reached $20.1 \%$. The sample then was prepared by the compaction method, the soil sample was evenly compacted in four layers to achieve the target dry density, the surface between each layer was fully shaved to facilitate the combination, and then the hollow core was cut out with a soil drill and a scraper. The prepared compacted hollow cylindrical loess sample is shown in Figure 3 , with a height of $100 \mathrm{~mm}$, an outer diameter of $70 \mathrm{~mm}$, and an inner diameter of $30 \mathrm{~mm}$.

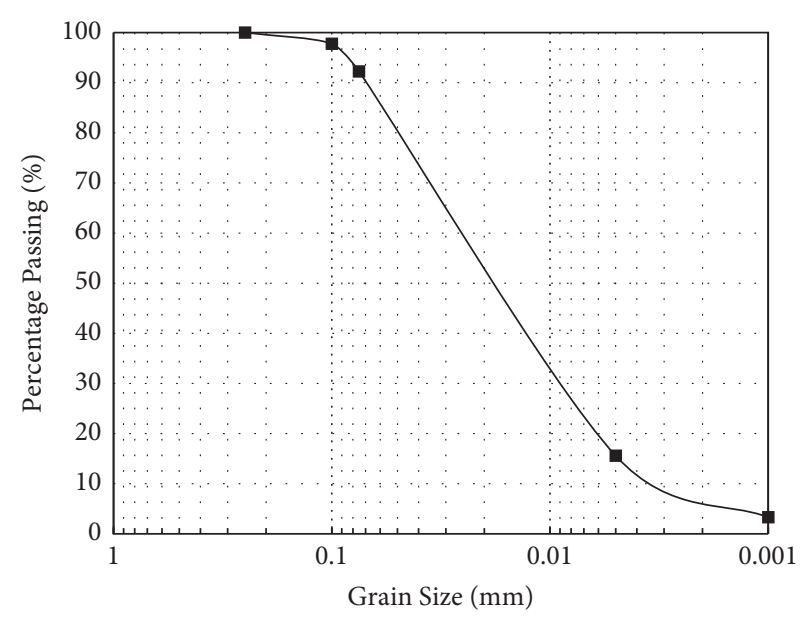

Figure 2: Grain size distribution curve of loess.

2.3. Test Loading Scheme. According to the results of test loading and stress analysis of hollow cylinders by Hight et al. $[25,26]$, the stresses on hollow cylinder specimens include axial stress $\sigma_{z}$, shear stress $\tau_{z \theta}$, radial stress $\sigma_{r}$, and hoop stress $\sigma_{\theta}$. These stresses are caused by the axial load $\mathrm{W}$, the torsion moment $M_{T}$ around the axis, the outer chamber pressure $P_{o}$, and the inner chamber pressure $P_{i}$. These forces can be calculated by formulas $(1) \sim(4)$. The application of these forces can be controlled by the stress parameters of the intermediate principal stress coefficient $b$, mean principal stress $p$, deviatoric stress ratio $\eta$, and principal stress direction angle $\alpha$, which are defined in formulas (5) $\sim(8)$. The stress state of the specimen and soil element is shown in Figure 4. 


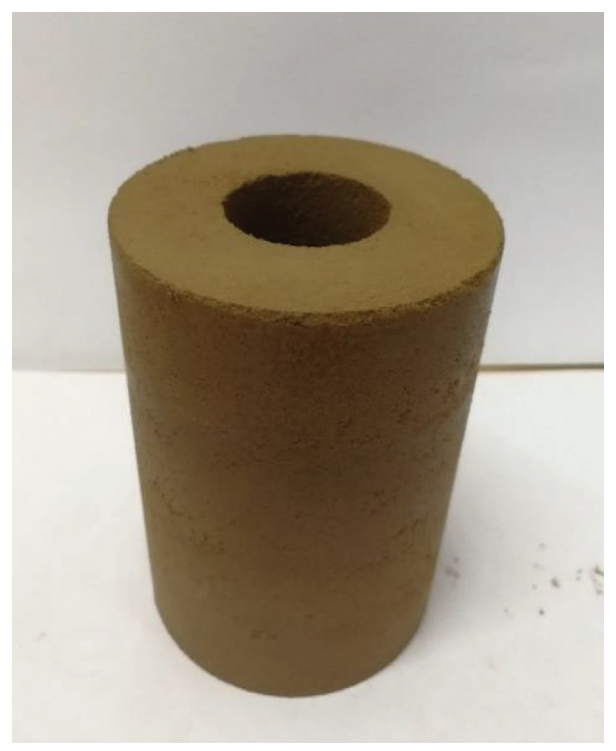

Figure 3: Compacted loess sample.

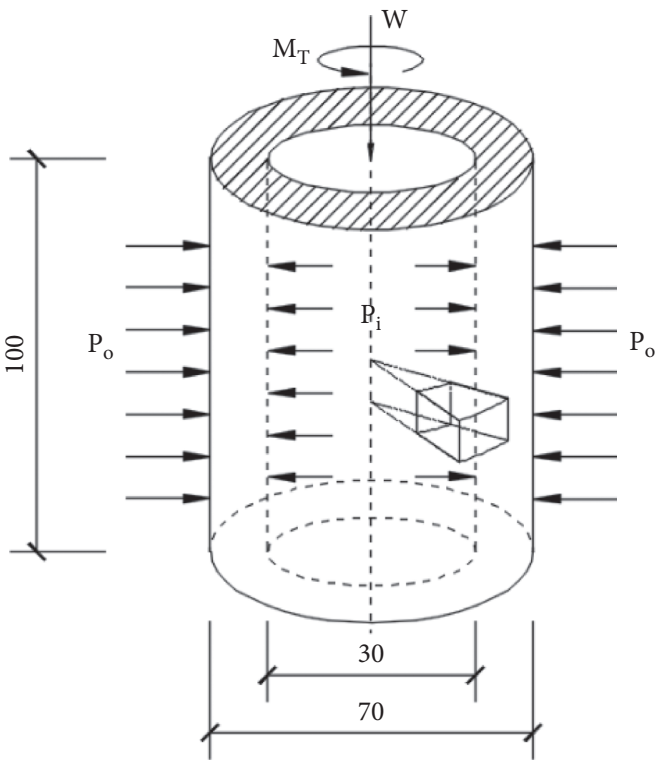

(a)

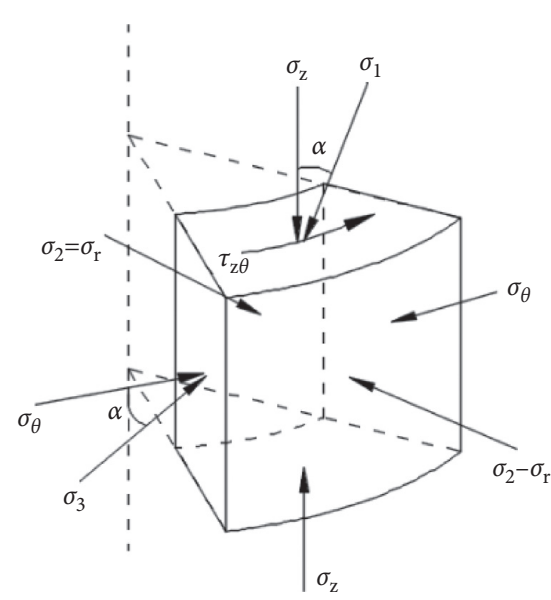

(b)

Figure 4: Schematic diagram of the stress on the sample. (a) Schematic diagram of sample size and force. (b) Soil element stress.

$$
\begin{aligned}
P_{0} & =\frac{A \sigma_{r}+B \sigma_{\theta}}{2 R_{o}}, \\
P_{i} & =\frac{A \sigma_{r}-B \sigma_{\theta}}{2 R_{i}}, \\
W & =\pi\left[\sigma_{z}\left(R_{o}^{2}-R_{i}^{2}\right)-\left(P_{0} R_{o}^{2}-P_{i} R_{i}^{2}\right)\right], \\
M_{T} & =\frac{2}{3} \pi \tau_{z \theta}\left(R_{o}^{3}-R_{i}^{3}\right),
\end{aligned}
$$

$$
\begin{aligned}
& \alpha=\frac{1}{2} \arctan \frac{2 \tau_{z \theta}}{\sigma_{z}-\sigma_{\theta}}, \\
& b=\frac{\sigma_{2}-\sigma_{3}}{\sigma_{1}-\sigma_{3}}, \\
& \eta=\frac{q}{p}, \\
& p=\frac{1}{3}\left(\sigma_{1}+\sigma_{2}+\sigma_{3}\right),
\end{aligned}
$$


where $R_{\mathrm{o}}$ is the outer radius of the sample; $R_{\mathrm{i}}$ is the inner radius of the sample; $A=R_{o}+R_{i} ; \mathrm{B}=R_{o}-R_{i}$; and $\sigma_{1}, \sigma_{2}$, and $\sigma_{3}$ are the major principal stress, the intermediate principal stress, and the minor principal stress, respectively. Deviator stress $q=1 / \sqrt{2}\left(\sqrt{\left(\sigma_{1}-\sigma_{2}\right)^{2}+\left(\sigma_{2}-\sigma_{3}\right)^{2}+\left(\sigma_{3}-\sigma_{1}\right)^{2}}\right)$, and $p$ is the mean principal stress. The deviatoric stress ratio is mainly used to characterize the relative magnitude relationship between the deviator stress and the spherical stress. Existing studies have proven that the deviatoric stress ratio has a certain influence on the deformation characteristics of soil [27]. This test mainly studies the effects of the mean principal stress, dry density, and deviatoric stress ratio on the dynamic modulus and damping ratio of compacted loess under the action of a circular stress path.

2.4. Test Program and Scheme. Some scholars studied the dynamic modulus and damping ratio of frozen soil by applying dynamic loading step by step and obtained reliable test results $[28,29]$. In this paper, referring to the above literature test method according to the principle of equivalent stress, and using a sine wave type, dynamic loads in the axial and torsional directions were applied step by step, at a load frequency of $1 \mathrm{~Hz}$. Each level of bidirectional dynamic load was applied for 20 cycles. The time history curve of the load is shown in Figure 5. To simulate the circular dynamic stress path, the amplitude of the axial dynamic stress $\sigma_{m}$ and the torsional shear stress $\tau_{m}$ is maintained at $\sigma_{m}=2 \tau_{m}$ at each stage of dynamic loading, and the phase difference between them is maintained at $90^{\circ}$. The ideal dynamic stress path in the $\tau_{z \theta d} \sim\left(\sigma_{\mathrm{zd}}-\sigma_{\theta d}\right) / 2$ stress coordinate system and an actual dynamic stress path in the test are shown in Figure 6(a) and 6(b), respectively, indicating that the test can better simulate the circular dynamic stress path. To ensure the stability of the data, a complete hysteresis loop of the 10th cycle was selected as the research object for each stage of loading, and all stresses and strains were taken as the average value of a cycle. In this paper, the influence of the average effective principal stress, dry density, and deviatoric stress ratio on the dynamic modulus and damping ratio of compacted loess under a circular dynamic stress path is considered. Under the action of additional stress and gravity stress of the soil under the building foundation, as the depth increases, the mean principal stress and deviator stress are constantly changing, so the deviator stress ratio is also different. There will be both isotropic stress state and anisotropic stress state in the foundation. In order to compare the test results with each other and reflect the influence of spherical stress and deviator stress on the dynamic modulus and damping ratio, three average principal stresses of $50 \mathrm{kPa}$, $100 \mathrm{kPa}$, and $200 \mathrm{kPa}$ and three deviatoric stress ratios of 0 , 0.2 , and 0.4 were selected. The specific test plan is shown in Table 2. The initial principal stress direction angle of all samples is $\alpha=0^{\circ}$, and the intermediate principal stress coefficient $b=0$. After the sample is installed, the consolidation stress is applied according to the test plan, and all the samples are consolidated by drainage. According to the specification [30], when the axial deformation of the sample within 5 minutes is less than $0.005 \mathrm{~mm}$, it is considered that its consolidation has reached stability. The two-way dynamic load is applied to the sample at the same time according to the test requirements.

\section{Results and Discussion}

In soil dynamics, the Hardin-Drnevich model is a widely used dynamic viscoelastic-plastic model that can describe the dynamic stress-strain relationship of soil by a hyperbolic curve. The model regards soil as a viscoelastic body. It assumes that the skeleton curve of the dynamic stress-dynamic strain relationship is a hyperbola and uses the equivalent dynamic shear modulus $G_{\text {eq }}$ and equivalent damping ratio $\lambda_{\text {eq }}$ reflect the nonlinearity and hysteresis of the soil dynamic stress-strain relationship, and both the shear modulus and damping ratio are expressed as functions of dynamic strain amplitude, namely, $G_{\mathrm{eq}}=G\left(\gamma_{d}\right)$ and $\lambda_{\mathrm{eq}}=\lambda\left(\gamma_{d}\right)$. When the dynamic shear strain $\gamma_{d}=\infty$, the curve takes the maximum dynamic shear stress $\tau_{d \max }$ as the asymptote. When $\gamma_{d}=0$, the tangent slope of the curve is the maximum shear modulus $G_{0}$. The expression of the torsional dynamic shear stress-strain relationship is as follows:

$$
\begin{gathered}
\tau_{d}=\frac{\gamma_{d}}{1 / G_{0}+\gamma_{d} / \tau_{d \max }}=\frac{\gamma_{d}}{a+b \gamma_{d}}, \\
\frac{1}{G_{d}}=\frac{\gamma_{d}}{\tau_{d}}=\frac{1}{G_{0}}+\frac{\gamma_{d}}{\tau_{d \max }}=a+b \gamma_{d},
\end{gathered}
$$

where $\tau_{d \max }$ is the maximum dynamic shear stress; $G_{0}$ is the initial dynamic shear modulus; $G_{d}$ is the dynamic shear modulus; and $a$ and $b$ are the intercept and slope corresponding to the straight line in the relationship curve $1 / G_{d} \sim \gamma_{d}$, respectively. The axial dynamic stress-strain relationship curve is similar.

\subsection{The Effect of the Mean Principal Stress on the Dynamic} Shear Modulus and Dynamic Compression Modulus. Figure 7 shows the dynamic compression modulus curve and dynamic shear modulus curve of different mean principal stresses of compacted loess with a dry density of $1.62 \mathrm{~g} /$ $\mathrm{cm}^{3}$ at the same deviatoric stress ratio. Figures $7(\mathrm{a}), 7(\mathrm{c})$, and 7 (e)shows the variation curve of the dynamic compression modulus with axial dynamic strain, and Figures 7(b), 7(d), and $7(\mathrm{f})$ shows the variation curve of the dynamic shear modulus with shear strain. The figure shows that the mean principal stress has an obvious influence on the dynamic compression modulus and dynamic shear modulus. When the same shear strain is reached under the same conditions, the larger the mean principal stress is, the greater the dynamic compression modulus and dynamic shear modulus are. The spherical stress represented by the mean principal stress can produce a larger "binding force" on the soil unit, and the dynamic deformation requires greater dynamic stress, so the dynamic compression modulus and dynamic shear modulus are both greater. Both the dynamic compression modulus and the dynamic shear modulus decrease continuously with the development of strain and finally tend 


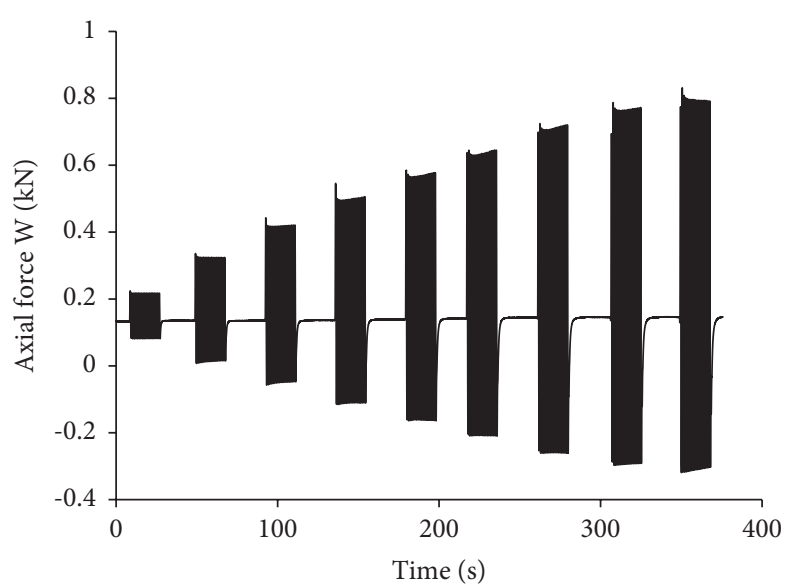

(a)

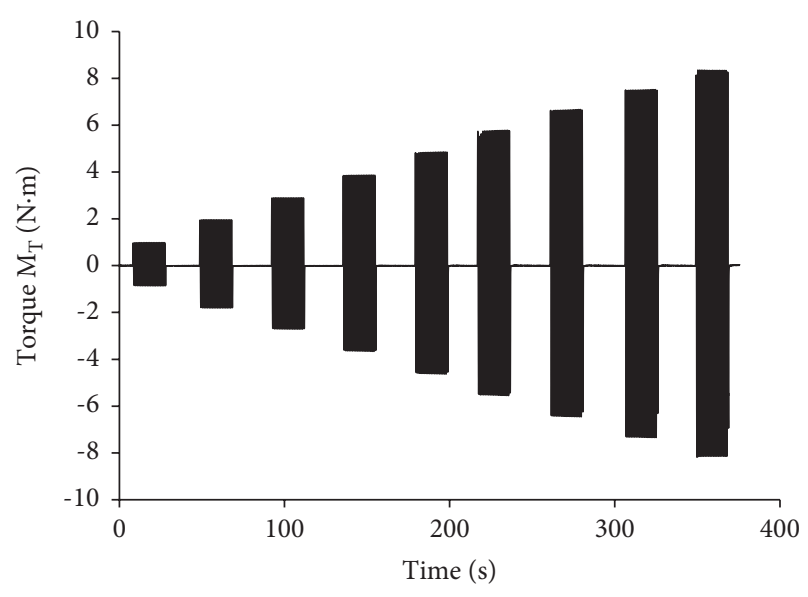

(b)

Figure 5: The actual time history curve of a certain test with two-way and step-by-step loading. (a) Time history curve of axial force loading step by step. (b) Time history curve of torque loading step by step.

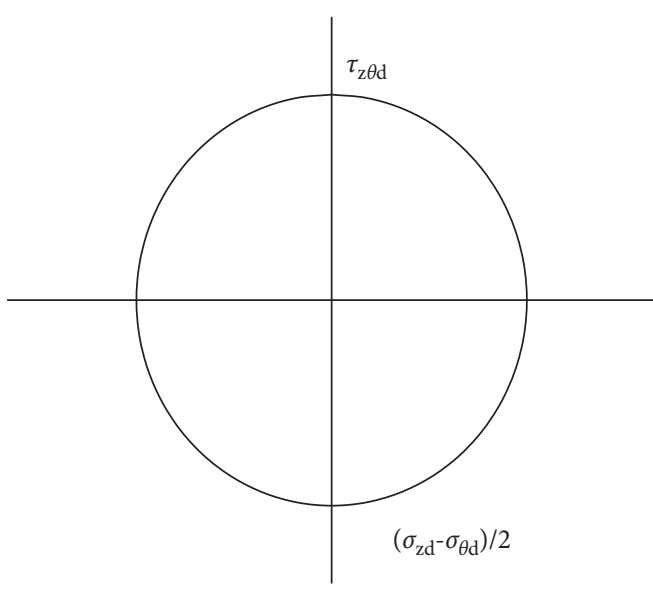

(a)

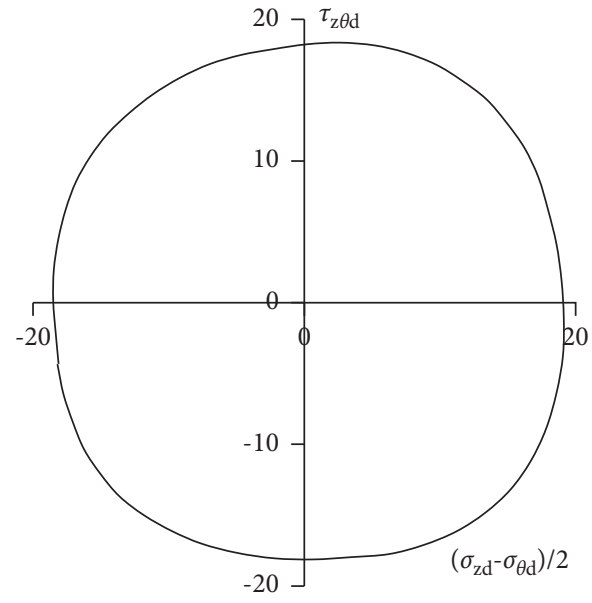

(b)

FIgURE 6: Ideal dynamic stress path and the certain dynamic stress path actually loaded. (a) Ideal circular dynamic stress path. (b) A cyclic dynamic stress path of measured loading.

TAble 2: Test plan.

\begin{tabular}{lccc}
\hline Dry density, $\rho_{\mathrm{d}}\left(\mathrm{g} / \mathrm{cm}^{3}\right)$ & Deviatoric stress ratio $(\eta)$ & Mean principal stress, $p(\mathrm{kPa})$ & Consolidation state \\
\hline 1.62 & 0 & $50,100,200$ & Isotropic consolidation \\
1.62 & 0.2 & $50,100,200$ & Anisotropic consolidation \\
1.62 & 0.4 & $50,100,200$ & Anisotropic consolidation \\
1.52 & 0 & 50 & Isotropic consolidation \\
1.52 & 0.2 & 50 & Anisotropic consolidation \\
1.52 & 0.4 & 50 & Anisotropic consolidation \\
1.44 & 0 & 50 & Isotropic consolidation \\
1.44 & 0.2 & 50 & Anisotropic consolidation \\
1.44 & 0.4 & 50 & Anisotropic consolidation \\
\hline
\end{tabular}

Note. Deviatoric stress ratio, $\eta=q / p$, where $p$ is the mean principal stress, $q=1 / \sqrt{2}\left(\sqrt{\left(\sigma_{1}-\sigma_{2}\right)^{2}+\left(\sigma_{2}-\sigma_{3}\right)^{2}+\left(\sigma_{3}-\sigma_{1}\right)^{2}}\right)$.

to be close and stable, but the degradation rate of the dynamic shear modulus is faster than that of the dynamic compression modulus in the early stage of strain development. This is due to the horizontal reciprocating torsional shear action that destroys the soil structure; microcracks appear inside, the deformation develops 


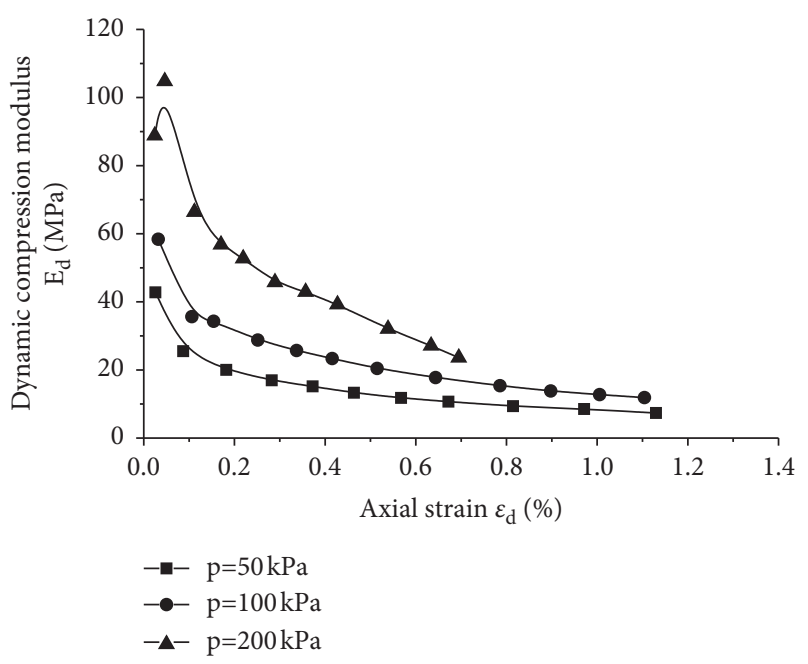

(a)

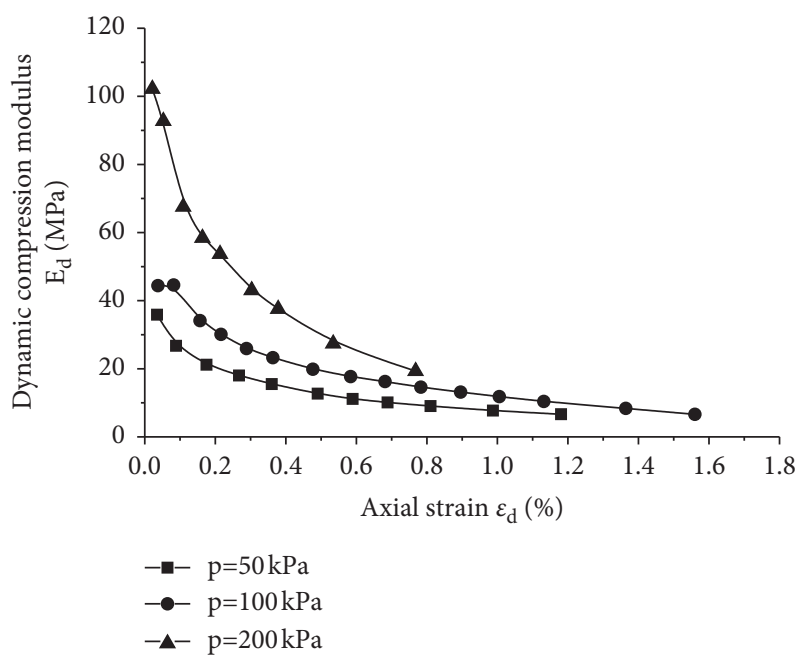

(c)

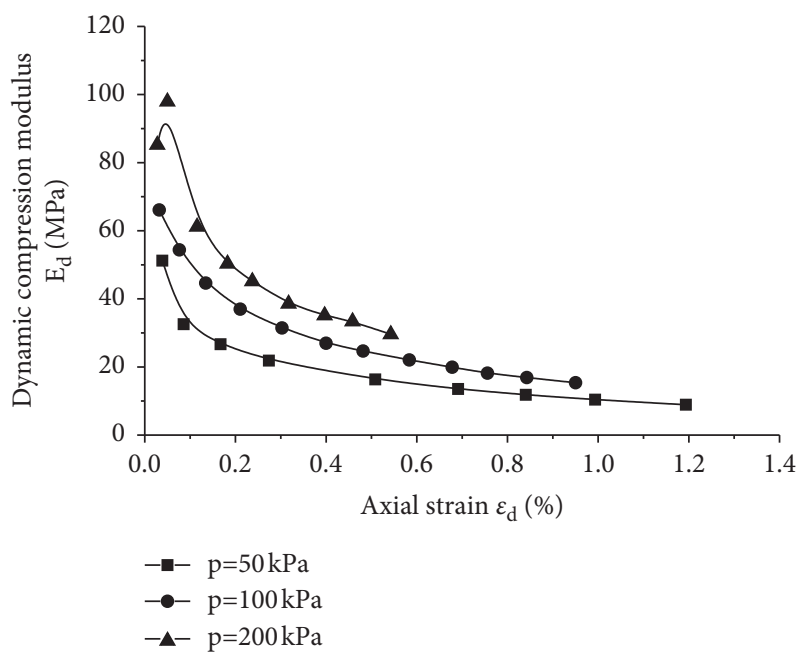

(e)

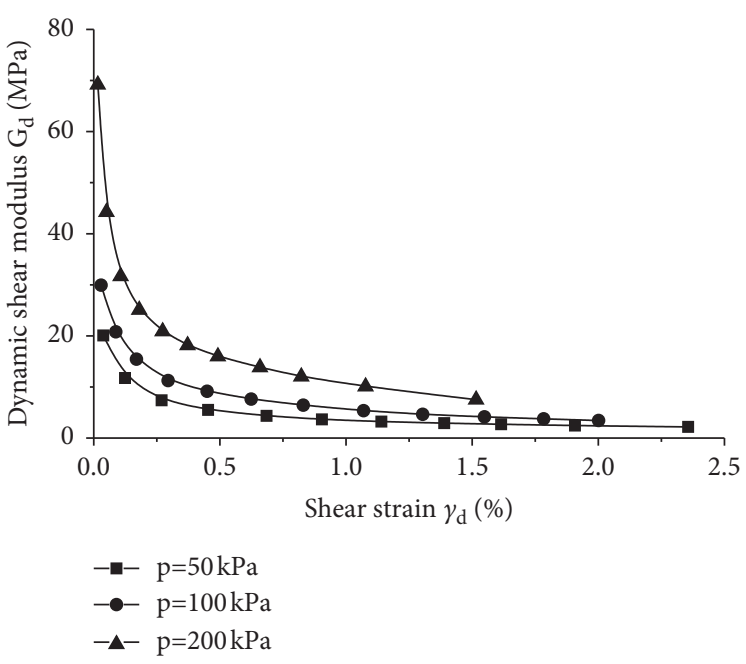

(b)

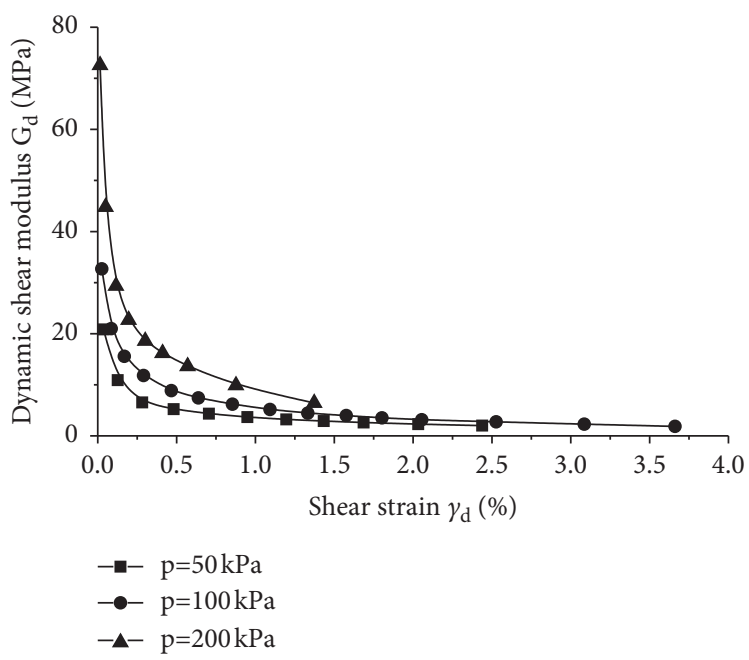

(d)

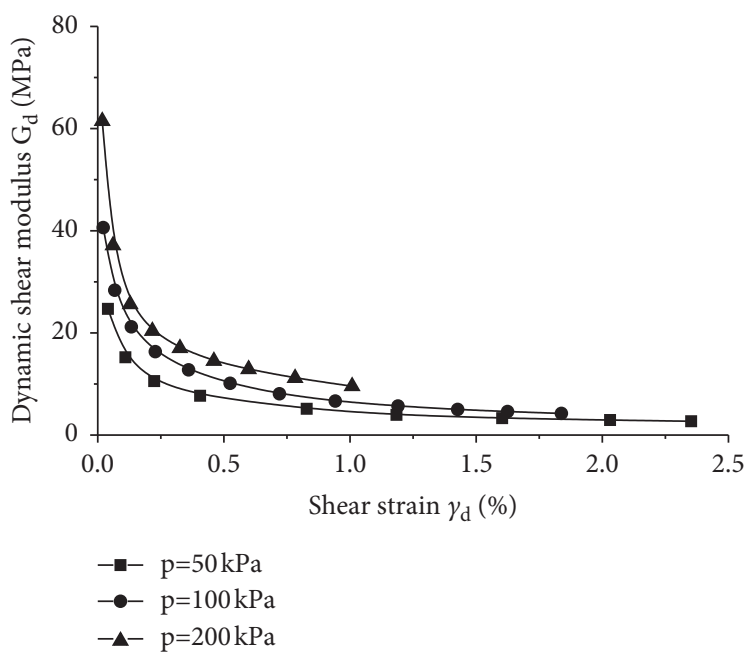

(f)

FiguRe 7: Curves of the dynamic compression modulus and dynamic shear modulus of compacted loess with different mean principal stresses under a circular dynamic stress path $\left(\rho_{d}=1.62 \mathrm{~g} / \mathrm{cm}^{3}\right)$. (a) Dynamic compression modulus curve $(\eta=0)$. (b) Dynamic shear modulus curve $(\eta=0)$. (c) Dynamic compression modulus curve $(\eta=0.2)$. (d) Dynamic shear modulus curve $(\eta=0.2)$. (e) Dynamic compression modulus curve $(\eta=0.4)$. (f) Dynamic shear modulus curve $(\eta=0.4)$. 
rapidly, and the dynamic modulus drops sharply. The small vertical dynamic stress will further compact the soil sample at the initial stage, so part of the dynamic compression modulus slightly increases in the initial stage of strain. However, due to the combined action of shear stress, most specimens exhibit compressive deformation until they fail with increasing dynamic stress. Therefore, the rate of decrease of the dynamic compression modulus in the initial stage of strain development is slower than that of the dynamic shear modulus.

\subsection{The Effect of Dry Density on Dynamic Shear Modulus and} Dynamic Compression Modulus. Figure 8 shows the dynamic compression modulus curves and dynamic shear modulus curves of different dry densities under the same deviatoric stress ratio when the mean principal stress is $50 \mathrm{kPa}$. Figures $8(\mathrm{a}), 8(\mathrm{c})$, and $8(\mathrm{e})$ show the variation curves of the dynamic compression modulus with axial dynamic strain when the deviatoric stress ratio is $0,0.2$, and 0.4 , respectively. Figures $8(\mathrm{~b}), 8(\mathrm{~d})$, and $8(\mathrm{f})$ shows the variation curves of the dynamic shear modulus with shear strain when the deviatoric stress is $0,0.2$, and 0.4 , respectively. It can be seen from the figure that the dry density has a significant effect on the dynamic compression modulus of compacted loess and has a slight effect on the dynamic shear modulus. The dynamic modulus of compacted loess gradually decreases with the development of dynamic strain, but in the later stage of dynamic strain development, although the dynamic stress and dynamic strain increase significantly, the dynamic modulus eventually tends to a stable value, which is usually defined as the residual dynamic modulus. Under the same conditions, the dynamic compression modulus that reaches the same dynamic strain increases with increasing dry density, especially when the axial dynamic strain is less than $1 \%$, and the residual dynamic compression modulus, which tends to be stable with the development of dynamic strain, is relatively large. Under the same conditions, the dynamic shear modulus reaching the same shear strain increases slightly with increasing dry density and finally tends to be basically the same as the residual dynamic shear modulus with the development of dynamic shear strain. It can be seen that that increasing the dry density of loess plays an important role in improving the dynamic compression modulus under axial strains below 1\%, but the effect of resisting dynamic shear deformation is not obvious.

\subsection{The Effect of the Deviatoric Stress Ratio on the Dynamic} Shear Modulus and Dynamic Compression Modulus. Since the deviatoric stress ratio has roughly the same influence on the dynamic compression modulus curves and dynamic shear modulus curves of compacted loess with different dry densities, only the test result with a dry density of $1.62 \mathrm{~g} / \mathrm{cm}^{3}$ is used as an example for illustration, as shown in Figure 9(a) and 9(b). It can be seen from the figure that the deviatoric stress ratio has a certain effect on the dynamic compression modulus curve and the dynamic shear modulus curve. When the deviatoric stress ratio is 0 and 0.2 , the dynamic compression modulus curves almost coincide.
However, when the deviatoric stress ratio reaches 0.4 , the dynamic compression modulus curve obviously improves. Although the dynamic shear modulus curve also shows the same rule, the increase in the dynamic shear modulus is relatively small. Existing studies have shown that the initial structural of undisturbed loess are easily destroyed by increased deviatoric stress, so the dynamic modulus of undisturbed loess decreases with the increase of the deviatoric stress ratio under cyclic torsional shear. The samples used in this test are all compacted loess, and the original structure has been destroyed during sample preparation, so the degree of compaction and the bite force between particles have become the main factors affecting the dynamic modulus [27]. Because the increase in the deviatoric stress ratio increases the axial force, the larger deviatoric stress ratio causes the soil sample to obtain a larger bite force in the consolidation stage; thus, the dynamic compression modulus and dynamic shear modulus of the soil sample are increased.

\subsection{Initial Dynamic Shear Modulus and Initial Dynamic} Compression Modulus under a Circular Dynamic Stress Path. The $1 / G_{d} \sim \gamma_{d}$ relationship curve obtained by equation (10) is a straight line. When the dynamic shear strain $\gamma_{d}$ or the dynamic strain $\varepsilon_{d}$ approaches 0 , the initial dynamic shear modulus and the initial dynamic elastic modulus can be obtained, that is, the reciprocal of intercept $a$, as shown in equations (11) and (12). When the dynamic shear strain $\gamma_{d}$ or the dynamic strain $\varepsilon_{d}$ approaches $\infty$, the maximum dynamic shear stress and the maximum dynamic stress can be obtained, that is, the reciprocal of the straight line slope $b$, as shown in equations (13) and (14).

$$
\begin{gathered}
G_{0}=\left.G_{d}\right|_{\gamma_{d} \longrightarrow 0}=\frac{1}{a_{1}}, \\
E_{0}=\left.E_{d}\right|_{\varepsilon_{d} \longrightarrow 0}=\frac{1}{a_{2}}, \\
\tau_{d \max }=\left.\tau_{d}\right|_{\gamma_{d} \longrightarrow+\infty}=\frac{1}{b_{1}}, \\
\sigma_{d \max }=\left.\sigma_{d}\right|_{\varepsilon_{d}} \longrightarrow+\infty=\frac{1}{b_{2}} .
\end{gathered}
$$

When the mean principal stress is $50 \mathrm{kPa}$, the initial dynamic modulus and maximum dynamic stress of compacted loess with different dry densities and deviatoric stress ratios under the action of the circular dynamic stress path are shown in Table 3. Except for individual data, the maximum axial dynamic stress and the maximum dynamic shear stress increase with increasing dry density and deviatoric stress ratio of the compacted loess under the same conditions. The initial dynamic compression modulus and initial dynamic shear modulus of compacted loess increase with increasing dry density. When the deviatoric stress ratio is $0,0.2$, and 0.4 , the initial dynamic compression modulus and the initial dynamic shear modulus of compacted loess with a dry density of $1.62 \mathrm{~g} / \mathrm{cm}^{3}$ compared to $1.44 \mathrm{~g} / \mathrm{cm}^{3}$ increases percentage as shown in Table 4 . The average 


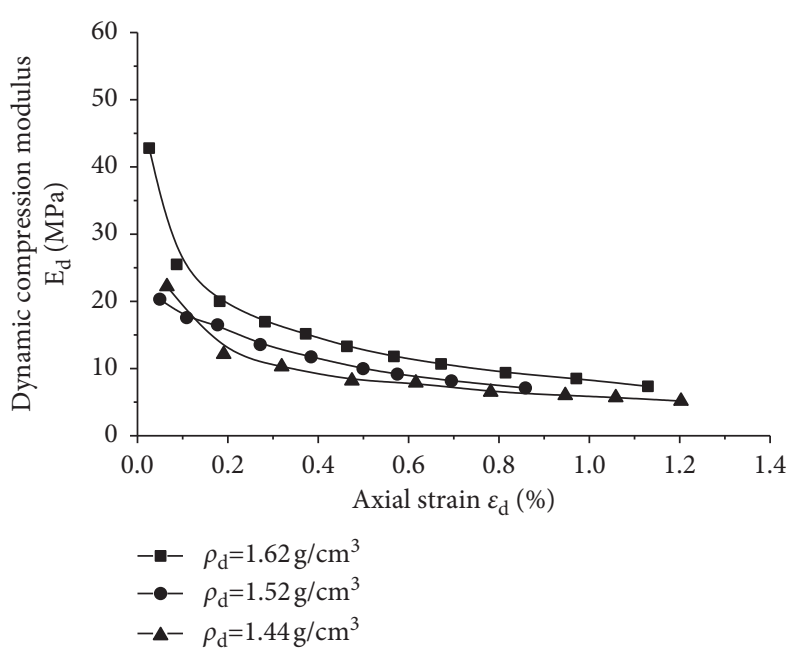

(a)

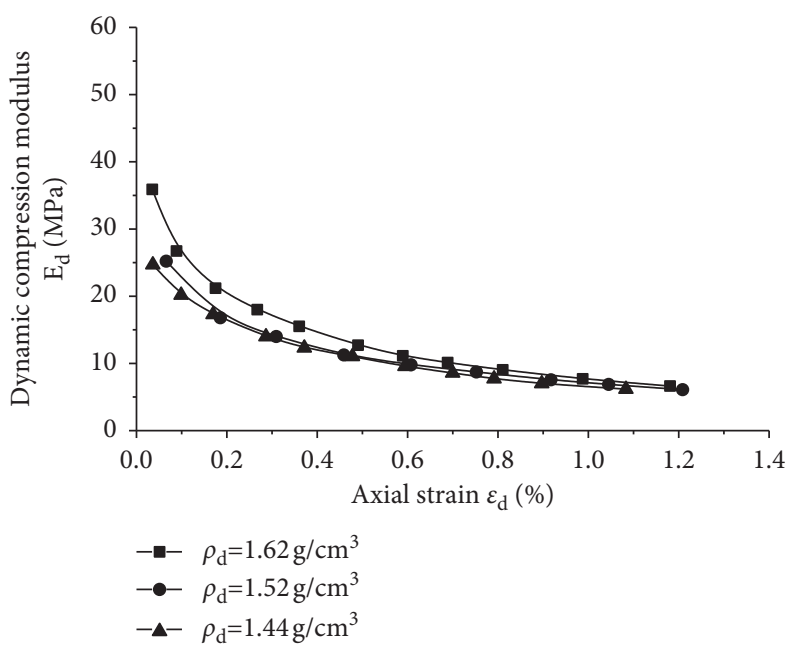

(c)

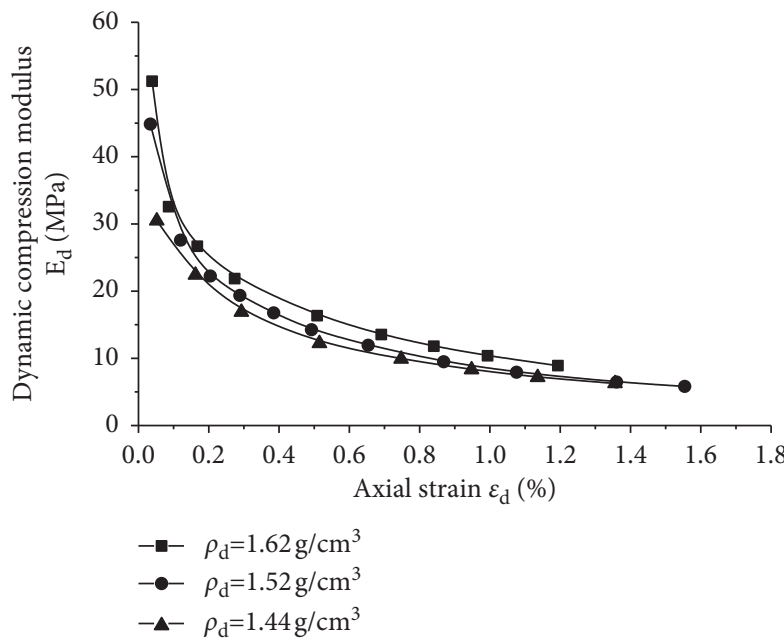

(e)

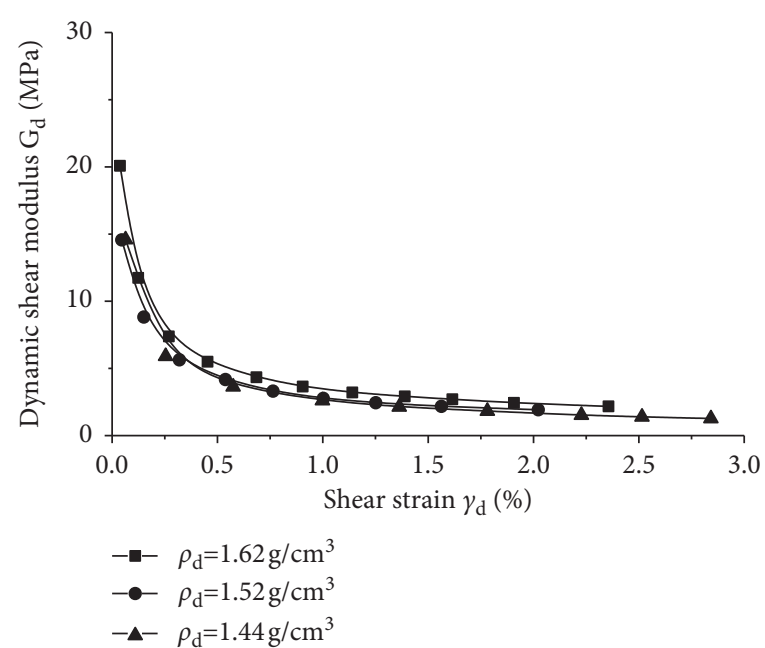

(b)

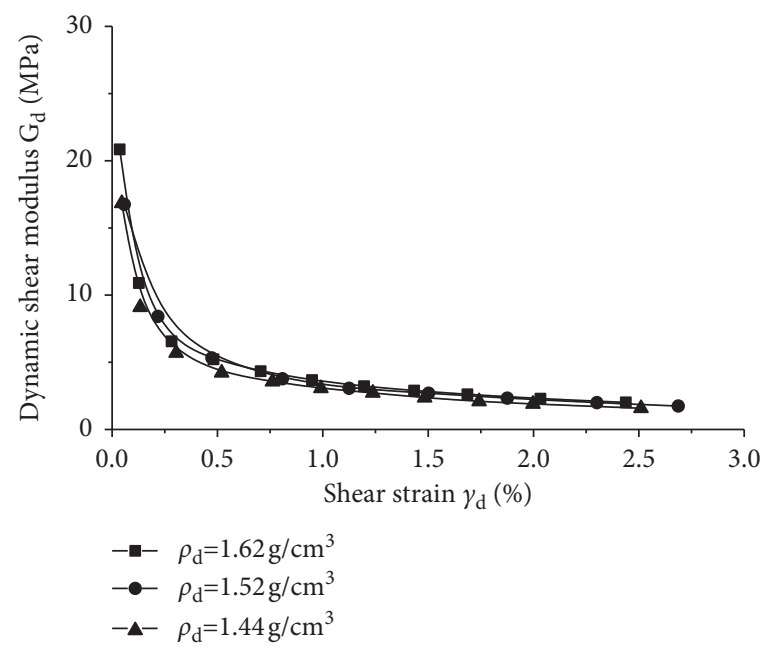

(d)

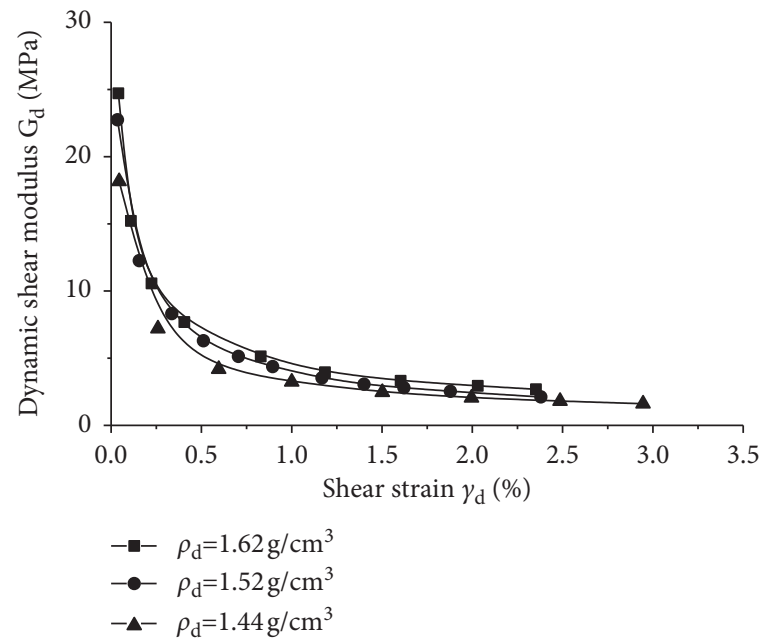

(f)

Figure 8: Curves of the dynamic compression modulus and dynamic shear modulus of compacted loess with different dry densities under a circular dynamic stress path $(p=50 \mathrm{kPa})$. (a) Dynamic compression modulus curve $(\eta=0)$. (b) Dynamic shear modulus curve $(\eta=0)$. (c) Dynamic compression modulus curve $(\eta=0.2)$. (d) Dynamic shear modulus curve $(\eta=0.2)$. (e) Dynamic compression modulus curve $(\eta=0.4)$. (f) Dynamic shear modulus curve $(\eta=0.4)$. 


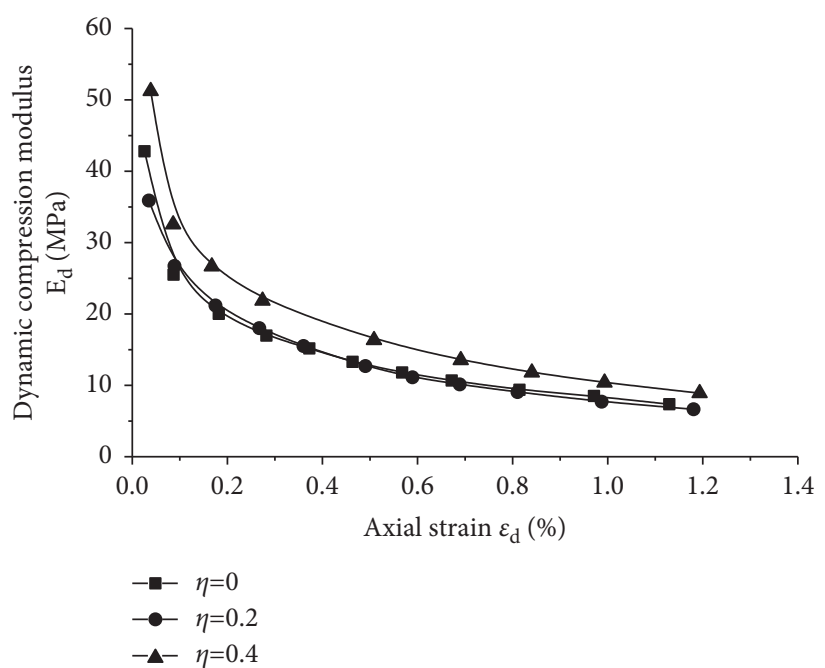

(a)

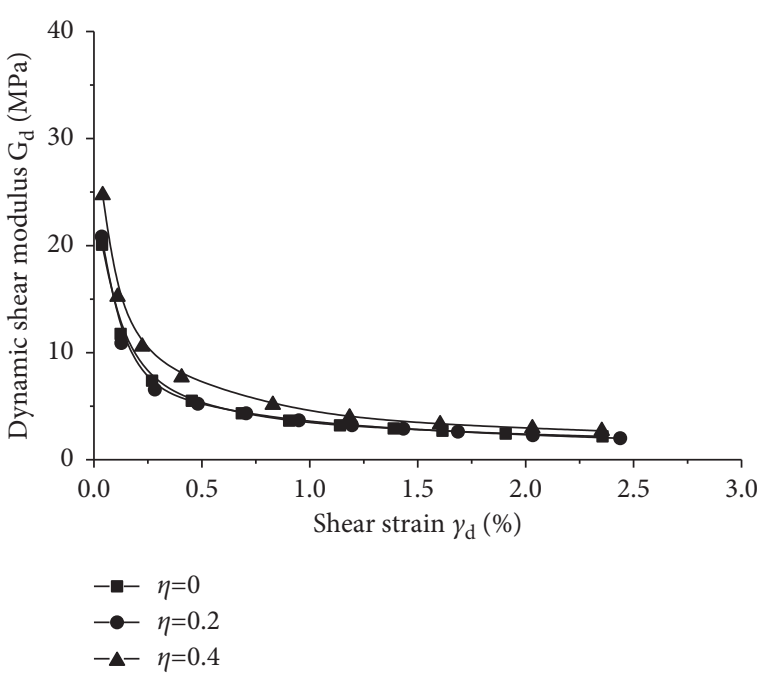

(b)

Figure 9: Curves of the dynamic compression modulus and dynamic shear modulus of compacted loess with different deviatoric stress ratios under a circular dynamic stress path $\left(\rho_{d}=1.62 \mathrm{~g} / \mathrm{cm}^{3}\right)$. (a) Dynamic compression modulus curve. (b) Dynamic shear modulus curve.

Table 3: Initial dynamic compression modulus and initial dynamic shear modulus of compacted loess with different dry densities and deviatoric stress ratios.

\begin{tabular}{lcccccccccccc}
\hline $\begin{array}{l}\text { Dry density } \\
\text { Deviator stress } \\
\text { ratio }\end{array}$ & $\begin{array}{c}\sigma_{d \max } \\
(\mathrm{kPa})\end{array}$ & $\begin{array}{c}E_{0} \\
(\mathrm{MPa})\end{array}$ & $\begin{array}{c}\tau_{d \max } \\
(\mathrm{kPa})\end{array}$ & $\begin{array}{c}G_{0} \\
(\mathrm{MPa})\end{array}$ & $\begin{array}{c}\sigma_{d \max } \\
(\mathrm{kPa})\end{array}$ & $\begin{array}{c}E_{0} \\
(\mathrm{MPa})\end{array}$ & $\begin{array}{c}\tau_{d \max } \\
(\mathrm{kPa})\end{array}$ & $\begin{array}{c}G_{0} \\
(\mathrm{MPa})\end{array}$ & $\begin{array}{c}\sigma_{d \max } \\
(\mathrm{kPa})\end{array}$ & $\begin{array}{c}E_{0} \\
(\mathrm{MPa})\end{array}$ & $\begin{array}{c}\tau_{d \max } \\
(\mathrm{kPa})\end{array}$ & $\begin{array}{c}G_{0} \\
(\mathrm{MPa})\end{array}$ \\
\hline$\eta=0$ & 105.9 & 33.78 & 57.8 & 11.36 & 87.6 & 23.36 & 43.5 & 10.09 & 83.6 & 18.48 & 40.5 & 8.55 \\
$\eta=0.2$ & 95.9 & 36.76 & 56.8 & 11.47 & 96.1 & 26.46 & 54.0 & 11.40 & 86.6 & 26.74 & 45.4 & 10.62 \\
$\eta=0.4$ & 133.3 & 44.44 & 70.8 & 16.26 & 104.1 & 43.86 & 55.2 & 16.86 & 103.9 & 33.78 & 53.4 & 10.29 \\
\hline
\end{tabular}

amplitude of the initial dynamic compressive modulus increase is higher than the dynamic shear modulus. With the increase in the deviatoric stress ratio, the initial dynamic compression modulus and initial dynamic shear modulus of compacted loess also increase. When the dry density is $1.62 \mathrm{~g} / \mathrm{cm}^{3}, 1.52 \mathrm{~g} / \mathrm{cm}^{3}$, and $1.44 \mathrm{~g} / \mathrm{cm}^{3}$, the initial dynamic compression modulus and the initial dynamic shear modulus of compacted loess with a deviatoric stress ratio of 0.4 compared to 0 increases percentage as shown in Table 5. This indicates that increasing the dry density and deviatoric stress ratio of compacted loess can greatly improve the bidirectional initial dynamic modulus, which is beneficial to the seismic resistance of soil under circular dynamic stress.

\subsection{Dynamic Shear Damping Ratio and Dynamic Compres-} sion Damping Ratio under the Action of a Circular Dynamic Stress Path. According to the principle of the equivalent dynamic visco-elastoplasic model, the 10th cycle of dynamic load applied to each stage is selected, and the hysteresis curve of each cyclic stress-strain relationship can be drawn. Most of the hysteresis curves are approximately elliptical, and the shear stress-strain relationship is taken as an example for illustration, as shown in Figure 10. The torsional damping ratio $\lambda_{\tau}$ is defined as equation (15). The dynamic stress-strain relationship in the axial direction is similar to that in the torsion-shear direction, so the axial damping ratio $\lambda_{z}$ is similar.

$$
\lambda_{\tau}=\frac{1}{4 \pi} \frac{\Delta S}{S} .
$$

In the formula, $\Delta S$ is the energy lost in a cycle, that is, the total area of the approximate ellipse. $S$ is the elastic strain energy, that is, the area of $\triangle \mathrm{OAB}$.

The curves of the dynamic compression damping ratio and dynamic shear damping ratio of compacted loess with three mean principal stresses of $50 \mathrm{kPa}, 100 \mathrm{kPa}$, and $200 \mathrm{kPa}$ under a circular stress path are calculated and analyzed when the dry density is $1.62 \mathrm{~g} / \mathrm{cm}^{3}$ and the deviatoric stress ratio is $0,0.2$, and 0.4 , respectively. Since the mean principal stress has roughly the same effect on the damping ratio under the same deviatoric stress ratio, the semilogarithmic curve of the damping ratio and strain with a deviatoric stress ratio of 0.2 is only taken as an example, as shown in Figure 11. It can be seen from the figure that the dynamic compression damping ratio and dynamic shear damping ratio can be fitted by equations (16) and (17), respectively:

$$
\begin{aligned}
& \lambda_{z}=k_{z} \log \left(\varepsilon_{d}\right)+l_{z}, \\
& \lambda_{\tau}=k_{\tau} \log \left(\gamma_{d}\right)+l_{\tau},
\end{aligned}
$$


TABLE 4: The percentage increase of the initial compressive modulus and initial shear modulus of compacted loess when the dry density is $1.62 \mathrm{~g} / \mathrm{cm}^{3}$ compared to $1.44 \mathrm{~g} / \mathrm{cm}^{3}$ at different deviator stress ratios.

\begin{tabular}{lcc}
\hline \multirow{2}{*}{ Deviator stress ratio } & \multicolumn{2}{c}{ Dynamic modulus } \\
& Relative increase percentage of $E_{0}(\%)$ & Relative increase percentage of $G_{0}(\%)$ \\
\hline$\eta=0$ & 82.8 & 32.9 \\
$\eta=0.2$ & 37.5 & 10.2 \\
$\eta=0.4$ & 31.6 & 58.0 \\
\hline
\end{tabular}

TABLE 5: The percentage increase of initial compressive modulus and initial shear modulus of compacted loess with different dry density when deviator stress ratio $\eta=0.4$ compared to $\eta=0$.

\begin{tabular}{lcc}
\hline Dry density & \multicolumn{2}{c}{ Dynamic modulus } \\
& Relative increase percentage of $E_{0}(\%)$ & Relative increase percentage of $G_{0}(\%)$ \\
\hline$\rho_{d}=1.62 \mathrm{~g} / \mathrm{cm}^{3}$ & 31.6 & 43.1 \\
$\rho_{d}=1.52 \mathrm{~g} / \mathrm{cm}^{3}$ & 87.8 & 67.1 \\
$\rho_{d}=1.44 \mathrm{~g} / \mathrm{cm}^{3}$ & 82.8 & 20.4 \\
\hline
\end{tabular}
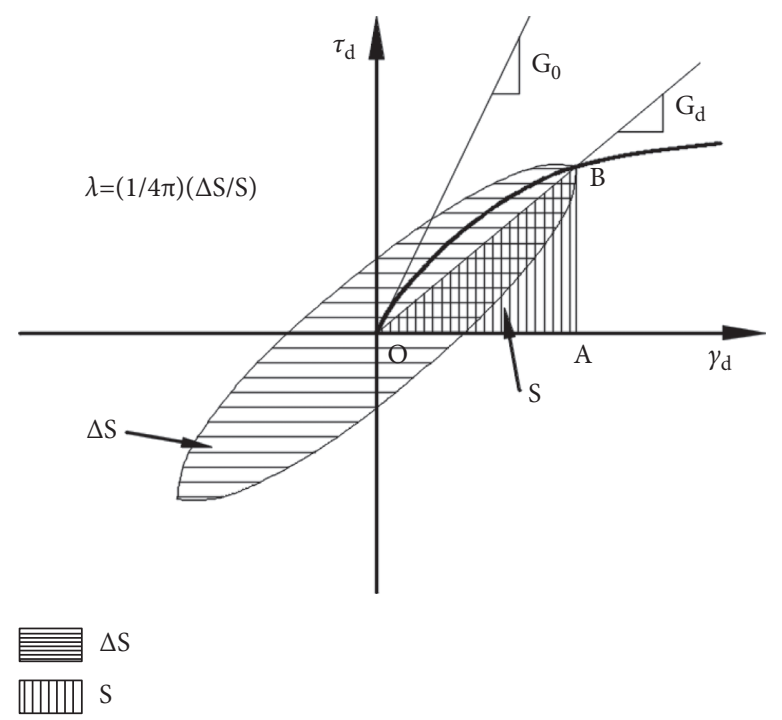

FIGURE 10: Schematic diagram of the hysteresis loop and damping ratio calculation.

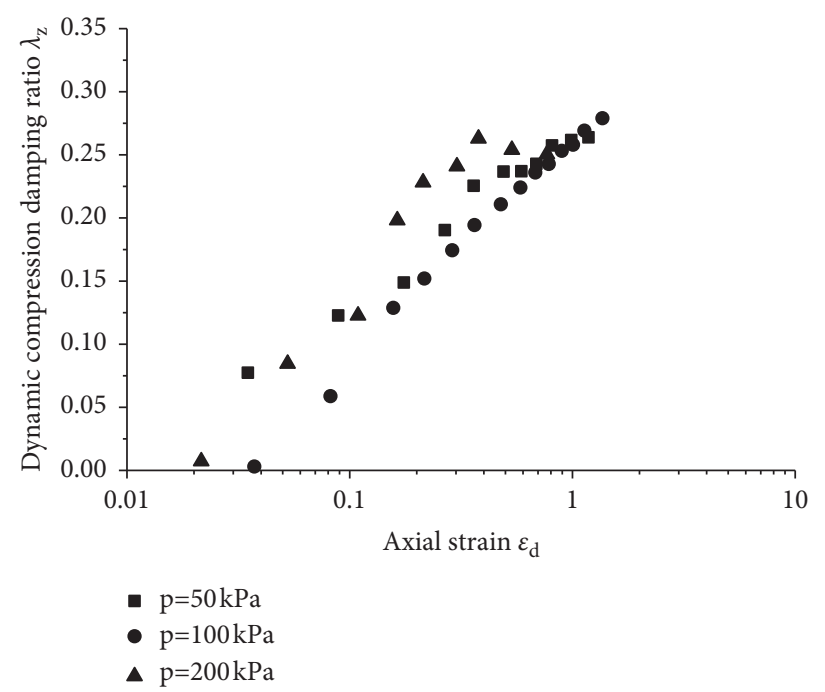

(a)

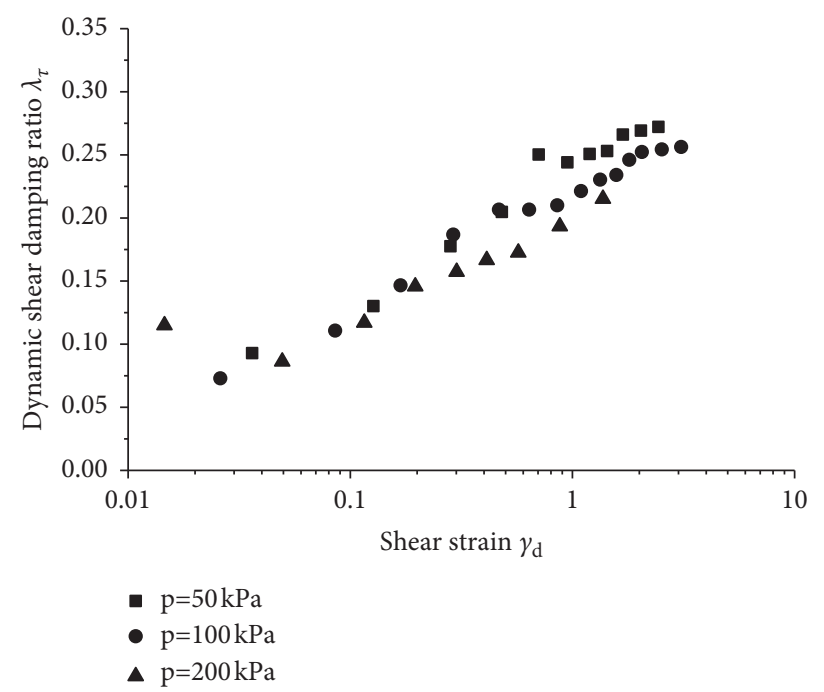

(b)

FIGURE 11: Scatter plot of the dynamic compression damping ratio and dynamic shear damping ratio of compacted loess with different mean principal stresses under the circular stress path $(\eta=0.2)$. (a) Dynamic compression damping ratio. (b) Dynamic shear damping ratio. 


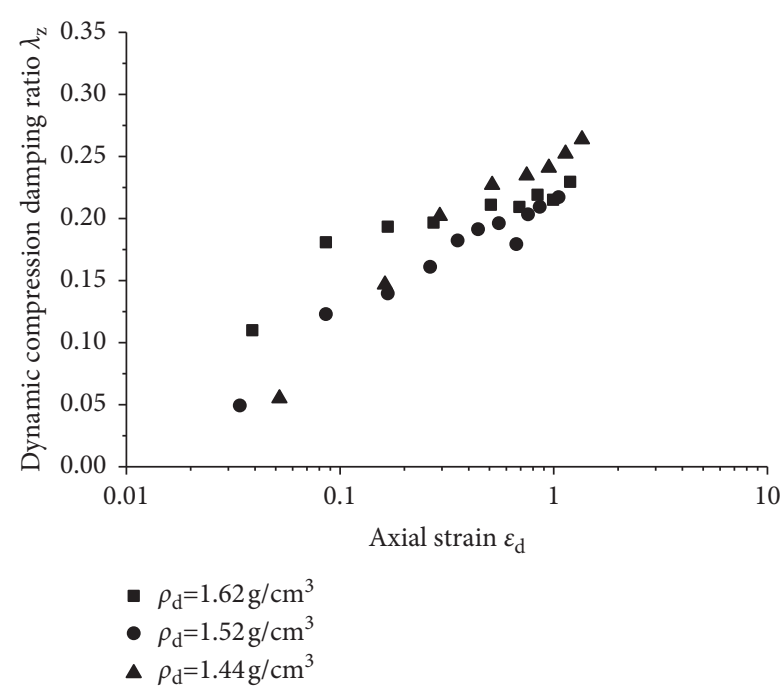

(a)

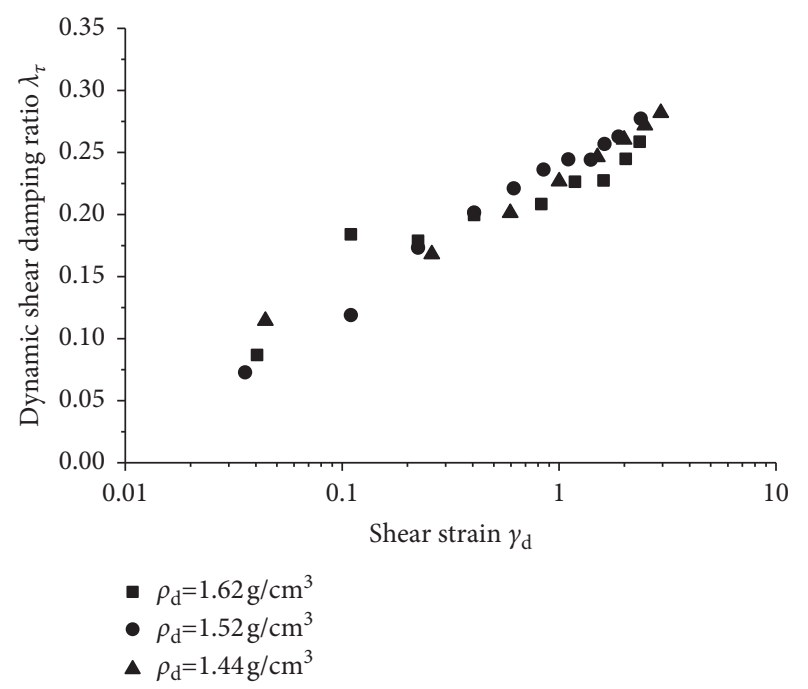

(b)

FIGURE 12: Scatter plot of the dynamic compression damping ratio and dynamic shear damping ratio of compacted loess with different dry densities under the circular stress path $(\eta=0.4)$. (a) Dynamic compression damping ratio. (b) Dynamic shear damping ratio.

where $\varepsilon_{d}$ is the axial dynamic strain, $\gamma_{d}$ is the dynamic shear strain, $k_{z}$ is the slope of the fitted straight line in the $\lambda_{z} \sim \log \left(\varepsilon_{d}\right)$ graph, $l_{z}$ is the intercept of the fitted straight line in the $\lambda_{z} \sim \log \left(\varepsilon_{d}\right)$ graph, $k_{\tau}$ is the slope of the fitted straight line in the $\lambda_{\tau} \sim \log \left(\gamma_{d}\right)$ graph, and $l_{\tau}$ is the intercept of the fitted straight line in the $\lambda_{\tau} \sim \log \left(\gamma_{d}\right)$ graph.

The dynamic compression damping ratio and dynamic shear damping ratio of compacted loess both increase with increasing dynamic strain. The slope of the straight line $k_{z}$ is obviously larger than $k_{\tau}$, indicating that the dynamic compression damping ratio increases faster than the dynamic shear damping ratio with the development of dynamic strain. However, the dynamic shear damping is larger than the dynamic compression damping ratio when it reaches the same dynamic strain at the beginning of the dynamic load. As the strain develops, the two eventually reach approximately 0.3 and become stable. It can be seen from the figure that the mean principal stress has a certain effect on the dynamic compression damping ratio and the dynamic shear damping ratio. Under the same conditions, the dynamic compression damping ratio reaching the same dynamic strain increases with increasing mean principal stress, and the dynamic shear damping ratio decreases with increasing mean principal stress.

In order to analyze the influence of dry density on damping ratio of compacted loess under circular dynamic stress path, the $\lambda_{z} \sim \log \left(\varepsilon_{d}\right)$ curve and $\lambda_{\tau} \sim \log \left(\gamma_{d}\right)$ curve of compacted loess with different dry density at the same deviatoric stress ratio are calculated when the mean principal stress is $50 \mathrm{kPa}$. Due to the influence of dry density on the damping ratio of compacted loess is almost the same at the same deviatoric stress ratio, only the semilogarithmic curve of the damping ratio and strain with a deviatoric stress ratio of 0.4 is taken as an example for illustration, as shown in Figure 12. It can be seen from the figure that the scatter points of the dynamic compression damping ratio and dynamic shear damping ratio of different dry densities are concentrated in a band-shaped area, which can be fitted with the straight lines of equations (16) and (17), respectively, and the slopes and intercepts of the two are close, indicating that the dry density has no effect on the dynamic compression damping ratio and the dynamic shear damping ratio of compacted loess, which is similar to the conclusions obtained by Wang et al. on the effect of dry density on the damping ratio under unidirectional torsional shear [31].

In order to study the influence of deviatoric stress ratio on damping ratio of compacted loess under circular dynamic stress path, the $\lambda_{z} \sim \log \left(\varepsilon_{d}\right)$ curve and $\lambda_{\tau} \sim \log \left(\gamma_{d}\right)$ curve of compacted loess with different deviatoric stress ratios under the same dry density are calculated when the mean principal stress is $50 \mathrm{kPa}$. The semilogarithmic curves of the damping ratio and strain of the three deviator stress ratios when the dry density is $1.62 \mathrm{~g} / \mathrm{cm}^{3}$ are illustrated in Figure 13. It can be seen from the figure that when the dynamic strain and shear strain are less than $1 \%$, the dynamic compression damping ratio and dynamic shear damping ratio of compacted loess slightly increase with the increase of deviator stress ratio. However, when the dynamic strain and the shear strain exceed $1 \%$, the influence of the deviatoric stress ratio becomes more obvious. When the same strain is reached, the larger the deviatoric stress ratio is, the smaller the dynamic compression damping ratio and the dynamic shear damping ratio are. This is different from the research results of Wang Zhijie and others on the damping ratio of undisturbed loess under cyclic torsional shear [27]. The damping ratio of undisturbed loess increases obviously with the increase of partial stress ratio under simple torsional shear, which is consistent with the influence law of compacted loess in this test when the strain is less than $1 \%$. However, when the dynamic strain is greater than $1 \%$, the bidirectional dynamic stress makes the soil particles more prone to dislocation. The decrease of soil particle contact 


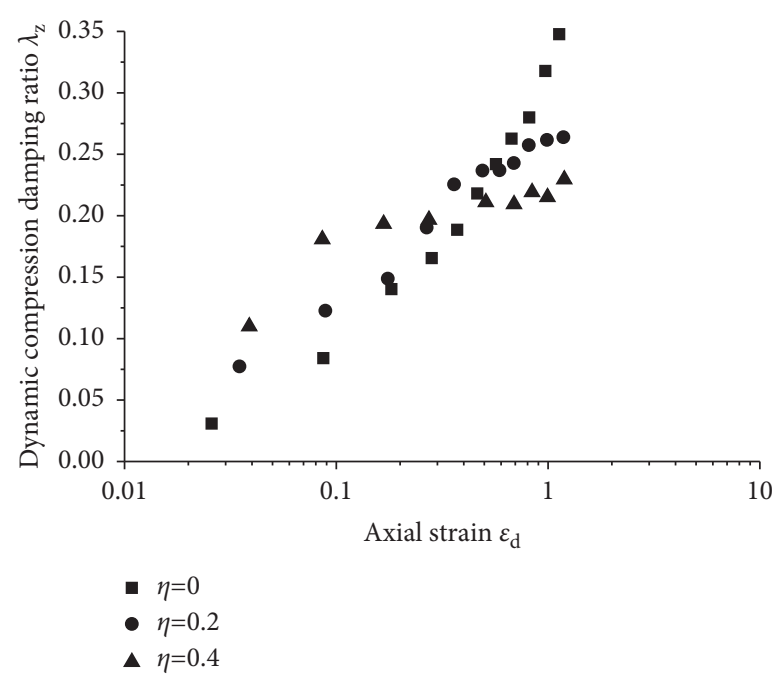

(a)

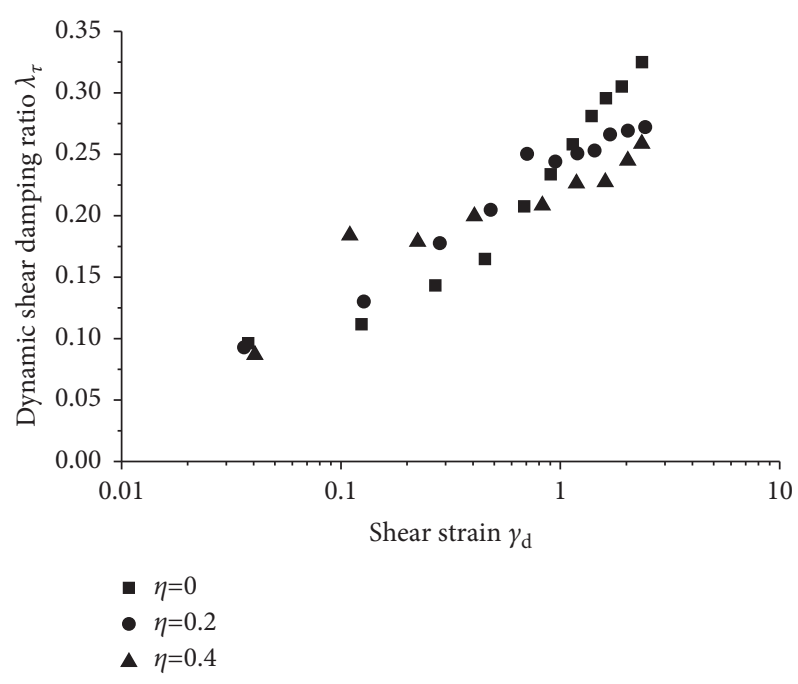

(b)

Figure 13: Scatter plot of the dynamic compression damping ratio and dynamic shear damping ratio of compacted loess with different deviatoric stress ratios under the circular stress path $\left(\rho_{d}=1.62 \mathrm{~g} / \mathrm{cm}^{3}\right)$. (a) Dynamic compression damping ratio. (b) Dynamic shear damping ratio.

point increases the energy dissipation capacity of loess, but the increase in deviator stress can accelerate the development of dynamic strain and reduce the energy dissipation capacity of loess.

\section{Conclusions}

In light of the fact that compacted loess is widely used as a foundation and subgrade in engineering construction in Northwest China, a hollow cylindrical torsion shear system is used to apply dynamic stress in two directions step by step to simulate the circular dynamic stress path caused by earthquakes, traffic, waves, etc. The effects of the mean principal stress, dry density, and deviatoric stress ratio on the dynamic compression modulus, dynamic shear modulus, dynamic compression damping ratio, and dynamic shear damping ratio of compacted loess are studied experimentally, and the main conclusions are summarized as follows:

(1) Under the action of the circular dynamic stress path, the mean principal stress has a significant effect on the dynamic compression modulus and dynamic shear modulus of compacted loess. When the same shear strain is reached under the same conditions, the greater the mean principal stress is, the larger the dynamic compression modulus and dynamic shear modulus are. The dry density of compacted loess has an obvious influence on the dynamic compression modulus. Under the same conditions, the dynamic compression modulus increases with increasing dry density. The effect of dry density on the dynamic shear modulus is relatively weak, and the dynamic shear modulus increases slightly with increasing dry density. The increase in the deviatoric stress ratio from 0 to 0.2 has little effect on the dynamic compression modulus and dynamic shear modulus of compacted loess. When the deviatoric stress ratio increases to 0.4 , the dynamic compression modulus and dynamic shear modulus increase significantly, which is different from the influence of deviator stress ratio on the dynamic shear modulus of undisturbed loess in the past.

(2) The larger the dry density and deviatoric stress ratio of compacted loess under the action of the circular dynamic stress path, the larger its initial dynamic compression modulus and initial dynamic shear modulus, and the average amplitude of the increase in the initial dynamic compression modulus is greater than that of the increase in the initial dynamic shear modulus. The greater the dry density and deviatoric stress ratio, the greater the maximum dynamic stress and maximum dynamic shear stress of compacted loess, and the higher the dynamic stress required for failure.

(3) Under the action of the circular dynamic stress path, the dynamic compression damping ratio and the dynamic shear damping ratio of the compacted loess can be well fitted by a straight line in semilogarithmic coordinates with the strain, and the damping ratio increases with increasing strain, finally stabilizing at approximately 0.3 . The dynamic compression damping ratio increases with increasing mean principal stress, and the dynamic shear damping ratio decreases with increasing mean principal stress. Dry density has no effect on the dynamic compression damping ratio and dynamic shear damping ratio of compacted loess. The deviatoric stress ratio has little effect on the dynamic compression damping ratio and dynamic shear damping ratio under small values of strain. When the dynamic 
strain exceeds $1 \%$, the greater the deviator stress is, the smaller the dynamic compression damping ratio and the dynamic shear damping ratio.

\section{Data Availability}

The data used to support the findings of this study are included within the article.

\section{Conflicts of Interest}

The authors declare that they have no conflicts of interest.

\section{Acknowledgments}

The authors appreciate the support of the National Science Foundation of China (no. 41272320) and the Key Scientific Research Projects of Higher Education Institutions in Henan Province, China (no. 21A560009).

\section{References}

[1] P. Subramaniam and S. Banerjee, "Shear modulus degradation model for cohesive soils," Soil Dynamics and Earthquake Engineering, vol. 53, pp. 210-216, 2013.

[2] P. Kallioglou, T. Tika, and K. Pitilakis, "Shear modulus and damping ratio of cohesive soils," Journal of Earthquake Engineering, vol. 12, no. 6, pp. 879-913, 2008.

[3] M. Y. Fattah, M. J. Al-Mosawi, and A. F. I. Al-Ameri, "Dynamic response of saturated soil - foundation system acted upon by vibration," Journal of Earthquake Engineering, vol. 21, no. 7, pp. 1158-1188, 2017.

[4] T. Feng, Y. Tang, Q. Wang, J. Zhang, and J. Song, "Experimental investigation of dynamic characteristics of subsea sand-silt mixtures," Advances in Civil Engineering, vol. 2019, Article ID 5619039, 9 pages, 2019.

[5] I. Towhata and K. Ishihara, "Undrained strength of sand undergoing cyclic rotation of principal stress axes," Soils and Foundations, vol. 25, no. 2, pp. 135-147, 1985.

[6] D. Zhang, F. Luo, Z. Zhu et al., "Study on mechanical properties of gravelly sand under different stress paths," Advances in Civil Engineering, vol. 2021, Article ID 8898814, 21 pages, 2021.

[7] K. W. Abdul Kaream, M. Y. Fattah, and Z. S. M. Khaled, "Response of circular machine foundation resting on sandy soil to harmonic excitation," Journal of Engineering Science \& Technology, vol. 15, no. 2, pp. 831-845, 2020.

[8] K. Abdul Kaream, M. Y. Fattah, and Z. Khaled, "Assessment of changes in shear strength parameters for soils below circular machine foundation," International Journal of Engineering, vol. 33, no. 8, pp. 1491-1498, 2020.

[9] K. Ishihara and I. Towhata, "Sand response to cyclic rotation of principal stress directions as induced by wave loads," Soils and Foundations, vol. 23, no. 4, pp. 11-26, 1983.

[10] K. Miura, S. Toki, and S. Miura, "Deformation prediction for anisotropic sand during the rotation of principal stress axes," Soils and Foundations, vol. 26, no. 3, pp. 42-56, 1986.

[11] A. Lashkari and M. Latifi, "A constitutive model for sand liquefaction under continuous rotation of principal stress axes," Mechanics Research Communications, vol. 36, no. 2, pp. 215-223, 2009.

[12] R. R. Zhou, F. Zhang, and K. Zhao, "Experimental study on excess pore pressure and deformation of saturated silt under complex stress paths," Journal of Natural Disasters, vol. 27, no. 6, pp. 173-179, 2018.

[13] F. Zhang, G. X. Chen, Q. Wu, and Z. Zhou, "Experimental study on undrained behavior of saturated silt subject to wave loading," Rock and Soil Mechanics, vol. 40, no. 7, pp. 2695-2702, 2019.

[14] C. Gu, J. Wang, Y. Cai, Z. Yang, and Y. Gao, "Undrained cyclic triaxial behavior of saturated clays under variable confining pressure," Soil Dynamics and Earthquake Engineering, vol. 40, pp. 118-128, 2012.

[15] C. Gu, Y. Q. Cai, and J. Wang, "Coupling effects of P-waves and S-waves based on cyclic triaxial tests with cyclic confining pressure," Chinese Journal of Geotechnical Engineering, vol. 34, no. 10, pp. 1903-1909, 2012.

[16] X. Hu, Y. Zhang, L. Guo et al., "Cyclic behavior of saturated soft clay under stress path with bidirectional shear stresses," Soil Dynamics and Earthquake Engineering, vol. 104, pp. 319-328, 2018.

[17] A. Inam, T. Ishikawa, and S. Miura, "Effect of principal stress axis rotation on cyclic plastic deformation characteristics of unsaturated base course material," Soils and Foundations, vol. 52, no. 3, pp. 465-480, 2012.

[18] C. Gallage, B. Dareeju, M. Dhanasekar, and T. Ishikawa, "Effects of principal stress axis rotation on unsaturated rail track foundation deterioration," Procedia Engineering, vol. 143, pp. 252-259, 2016.

[19] B. Dareeju, C. Gallage, T. Ishikawa, and M. Dhanasekar, "Effects of principal stress axis rotation on cyclic deformation characteristics of rail track subgrade materials," Soils and Foundations, vol. 57, no. 3, pp. 423-438, 2017.

[20] J. Qian, Z. Du, X. Lu, X. Gu, and M. Huang, "Effects of principal stress rotation on stress-strain behaviors of saturated clay under traffic-load-induced stress path," Soils and Foundations, vol. 59, no. 1, pp. 41-55, 2019.

[21] Z. T. Wang, P. Liu, D. Jeng, and Q. Yang, "Cyclic strength of sand under a nonstandard elliptical rotation stress path induced by wave loading," Journal of Hydrodynamics, vol. 29, no. 1, pp. 89-95, 2017.

[22] Y. Wang, Y. Gao, L. Guo et al., "Cyclic response of natural soft marine clay under principal stress rotation as induced by wave loads," Ocean Engineering, vol. 129, pp. 191-202, 2017.

[23] D. W. Cheng, Y. S. Luo, L. G. Yang, and X. Chen, "Effect of complex initial stress conditions on dynamic deformation behaviors of compacted loess," Applied Mechanics and Materials, vol. 90-93, pp. 67-73, 2011.

[24] R. Wang, Z. Hu, X. Ren, F. Li, and F. Zhang, "Dynamic modulus and damping ratio of compacted loess under longterm traffic loading," Road Materials and Pavement Design, vol. 2011, Article ID 1924232, 15 pages, 2021.

[25] D. W. Hight, A. Gens, and M. J. Symes, "The development of a new hollow cylinder apparatus for investigating the effects of principal stress rotation in soils," Géotechnique, vol. 33, no. 4, pp. 355-383, 1983.

[26] H. J. Wang, R. F. Shen, and Q. G. Ma, "Dynamic strength of soil under multi-direction loading," Journal of Tsinghua University, vol. 4, pp. 93-98, 1996.

[27] Z. J. Wang, Y. S. Luo, H. Guo, and H. Tian, "Effects of initial deviatoric stress ratios on dynamic shear modulus and damping ratio of undisturbed loess in China," Engineering Geology, vol. 143-144, pp. 43-50, 2012.

[28] F. Zhao, L. Chang, and W. Zhang, "Experimental investigation of dynamic shear modulus and damping ratio of Qinghai-Tibet frozen silt under multi-stage cyclic loading," Cold Regions Science and Technology, vol. 170, Article ID 102938, 2020. 
[29] X. Z. Ling, F. Zhang, Q. L. Li, L. S. An, and J. H. Wang, "Dynamic shear modulus and damping ratio of frozen compacted sand subjected to freeze-thaw cycle under multistage cyclic loading," Soil Dynamics and Earthquake Engineering, vol. 76, pp. 111-121, 2015.

[30] National standards of People's Republic of China, Standard for Geotechnical Testing Method: GB/T 50123-2019, China Planning Press, Beijing, China, 2019.

[31] Z. J. Wang, Y. S. Luo, and D. Y. Tan, "Experimental study on the effects of dry density on dynamic properties of remodeled loess under condition of pre-shearing stress," Northwestern Seismological Journal, vol. 33, no. 4, pp. 349-353, 2011. 